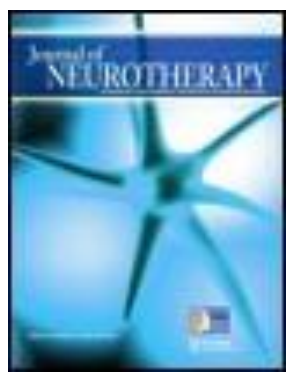

Journal of Neurotherapy: Investigations in Neuromodulation, Neurofeedback and Applied Neuroscience

\title{
Changes After EEG Biofeedback and Cognitive Retraining in Adults with Mild Traumatic Brain Injury and Attention Deficit Hyperactivity Disorder
}

Timothy P. Tinius PhD \& Kathleen A. Tinius MSW

Published online: 17 Oct 2008.

To cite this article: Timothy P. Tinius PhD \& Kathleen A. Tinius MSW (2000) Changes After EEG Biofeedback and Cognitive Retraining in Adults with Mild Traumatic

Brain Injury and Attention Deficit Hyperactivity Disorder, Journal of Neurotherapy: Investigations in Neuromodulation, Neurofeedback and Applied Neuroscience, 4:2, 27-44

To link to this article: http://dx.doi.org/10.1300/J184v04n02_05

\section{PLEASE SCROLL DOWN FOR ARTICLE}

(c) International Society for Neurofeedback and Research (ISNR), all rights reserved. This article (the "Article") may be accessed online from ISNR at no charge. The Article may be viewed online, stored in electronic or physical form, or archived for research, teaching, and private study purposes. The Article may be archived in public libraries or university libraries at the direction of said public library or university library. Any other reproduction of the Article for redistribution, sale, resale, loan, sublicensing, systematic supply, or other distribution, including both physical and electronic reproduction for such purposes, is expressly forbidden. Preparing or reproducing derivative works of this article is expressly forbidden. ISNR makes no representation or warranty as to the accuracy or completeness of any content in the Article. From 1995 to 2013 the Journal of Neurotherapy was the official publication of ISNR (WwW. Isnr.org); on April 27, 2016 ISNR acquired the journal from Taylor \& Francis Group, LLC. In 2014, ISNR established its official open-access journal NeuroRegulation (ISSN: 2373-0587; www.neuroregulation.org).

THIS OPEN-ACCESS CONTENT MADE POSSIBLE BY THESE GENEROUS SPONSORS

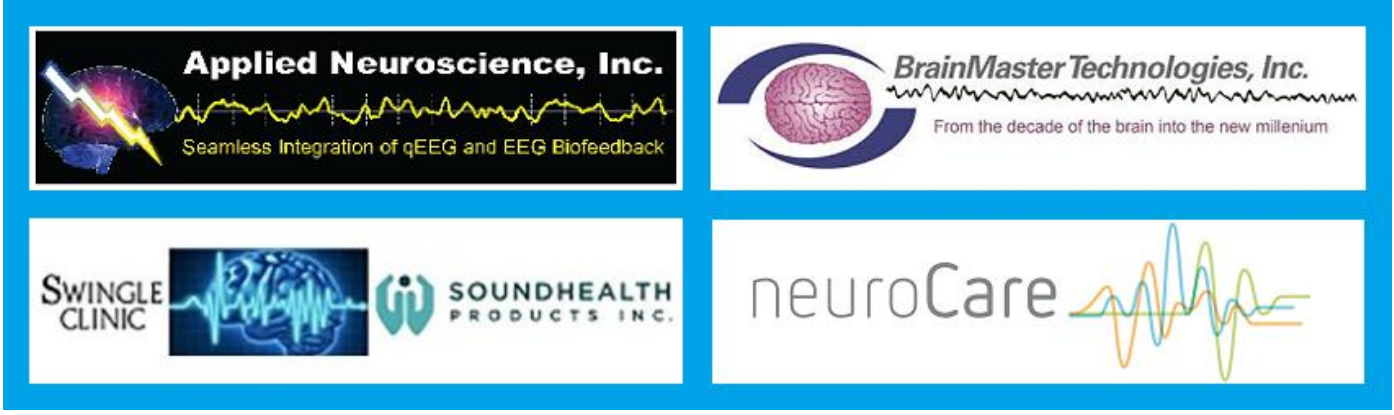




\title{
Changes After EEG Biofeedback and Cognitive Retraining in Adults with Mild Traumatic Brain Injury and Attention Deficit Hyperactivity Disorder
}

\author{
Timothy P. Tinius, $\mathrm{PhD}$ \\ Kathleen A. Tinius, MSW
}

\begin{abstract}
Introduction. Adults diagnosed with mild traumatic brain injury (mTBI) or Attention Deficit Hyperactivity Disorder (ADHD) were treated with EEG Biofeedback and cognitive retraining.

Methods. Psychological and neuropsychological tests were completed at pre-treatment and post-treatment and compared to a normal control group that did not receive training, but tested on two occasions.

Results. The results found significant improvement on full scale attention and full scale response accuracy of a continuous performance task in the mTBI and ADHD groups compared to the control group. A self report showed a significant decline in symptoms in the mTBI and ADHD groups compared to the control group. Errors on a problem solving task decreased only in the mTBI group.

Discussion. The treatment model used in this study showed significant improvement in the sustained attention of individuals diagnosed with mTBI and ADHD after twenty treatment sessions.
\end{abstract}

KEYWORDS. EEG biofeedback, neurofeedback, neurotherapy, cognitive retraining, cognitive rehabilitation

Timothy P. Tinius, PhD, is Licensed Psychologist and Kathleen A. Tinius, MSW, is Social Worker, both in private practice in Sauk Rapids, MN.

Address correspondence to: Timothy P. Tinius, PhD, 225 Benton Drive North, Suite 104, Sauk Rapids, MN 56379 (E-mail: tinius@cloudnet.com).

Journal of Neurotherapy, Vol. 4(2) 2000

Copyright (C) 2000 ISNR. All rights reserved. 


\section{INTRODUCTION}

Persons with mild Traumatic Brain Injury (mTBI) can have neuropsychological, emotional, and psychosocial changes despite a minimal loss of consciousness (Gasquoine, 1997), with the most important problem in sustained attention and concentration (Lezak, 1995). Changes in auditory (Gronwall, 1989) and visual (Gentilini, Nichelli, \& Schoenhuber, 1989) sustained attention were described in separate reviews. Most recently, adults diagnosed with either mTBI or Attention Deficit Hyperactivity Disorder, inattentive subtype (American Psychiatric Association, 1994) showed significant changes in sustained attention on the Intermediate Visual and Auditory (IVA) Continuous Performance Test (CPT) (Tinius, 2000).

Research found significant Quantitative Electroencephalography (QEEG) differences between adolescent males with ADHD (Mann, Lubar, Zimmerman, Miller, \& Muenchen, 1990) and in adults with mTBI (Thatcher, Walker, Gerson, \& Geisler, 1989) and normals. Given these changes in attention and EEG in persons with mTBI and ADHD, EEG biofeedback or neurotherapy was used for treatment. Changes after treatment with EEG biofeedback were reported in adolescents with ADHD (Lubar \& Lubar, 1984) and EEG biofeedback was found to be as effective as stimulant medication in adolescents with ADHD (Rossiter \& La Vaque, 1995). For persons with mTBI, treatment with EEG biofeedback showed significant changes in several case studies (Byers, 1995; Ayers, 1993). The purpose of this study was to measure the changes in adults diagnosed with mTBI or ADHD who were treated with EEG biofeedback in combination with cognitive retraining compared to a control group that did not receive training. It was hypothesized that scores for sustained attention would be less in the mTBI and ADHD group before treatment and would significantly increase as a result of treatment. It was also hypothesized that a self report of symptoms in the treatment groups would decrease as a result of treatment.

\section{METHOD}

\section{Participants}

There were forty-four individuals (seventeen males, twenty-seven females) in this study. The control group consisted of fifteen individuals (eight males, seven females) from the local community recruited to participate in the study. The control group was screened and had a negative history of neurological and neuropsychological problems. The mild traumatic brain injury group consisted of sixteen individuals (five males, eleven females) 
referred for a neuropsychological evaluation and received a diagnosis of mild traumatic brain injury (mTBI) through interview, history, and neuropsychological tests. Participants in the mTBI group met the criteria of loss of consciousness of less than thirty minutes, post-traumatic amnesia of less than twenty-four hours, and/or feeling dazed or stunned at the time of injury (Mild Traumatic Brain Injury Committee of the Head Injury Interdisciplinary Special Interest Group of the American College of Rehabilitation Medicine, 1993). The ADHD group consisted of thirteen individuals (four males, nine females) referred for a psychological evaluation and received a diagnosis of ADHD, inattentive type by achieving 6 of 9 criteria for inattention in DSMIV (APA, 1994). The demographic data of the control, mTBI, and ADHD groups is shown in Table 1.

\section{Procedure}

All individuals in the study completed the Intermediate Visual and Auditory (IVA) CPT (Sandford \& Turner, 1995), the Neuropsychological Impairment Scales (NIS; O'Donnell, DeSoto, Desoto, \& Reynolds, 1984), the Wechsler Adult Intelligence Scale-Revised (WAIS-R; Wechsler, 1981) and the Wisconsin Card Sorting Test (WCST; Heaton, Chelune, Talley, Kay, \& Curtiss, 1993) pre- and post-treatment. For the mTBI and ADHD groups, treatment usually lasted for twenty sessions, but the goal was to complete treatment as quickly as possible. Clinical experience with several cases showed that twenty sessions could be an optimal stopping point. Three individuals in the ADHD group completed treatment in less than twenty sessions due to termination of insurance benefits. The control group was tested on two separate occasions approximately three to seventeen weeks apart and did not receive any treatment. All testing was completed in accordance with the standardized procedures outlined in the administration manuals.

All individuals in the mTBI and ADHD groups completed simultaneous EEG biofeedback and cognitive retraining during the treatment sessions.

TABLE 1. Means and Standard Deviations for Demographic Variables.

\begin{tabular}{|lccc|}
\hline Variable & Control & mTBI & ADHD \\
\hline Age & $25.1 \quad(6.8)$ & $29.0(11.4)$ & $37.4(10.2)$ \\
Education & $15.6(1.7)$ & $12.6(2.1)$ & $13.3(2.4)$ \\
Days Between Testing & $58.7(29.8)$ & $153.1(59.9)$ & $158.3(60.9)$ \\
Number of Sessions & & $21.2 \quad(4.7)$ & $18.5 \quad(4.3)$ \\
\hline
\end{tabular}


Each treatment session was thirty to forty-five minutes long and consisted of Audio and Visual Feedback from the Biolex EEG computerized biofeedback software. The electrode placement and type of feedback were based upon clinical symptoms and a 19-channel brain map from the Thatcher Reference Database (Thatcher, 1987). The treatment decisions are shown in Table 2. The electrode placement and type of feedback for each person in the treatment groups are shown in Appendix 1. The electrode placement could change in a session given the current symptoms and performance from the previous session. The treatment sessions were tailored to the individual symptoms, pre-treatment testing, and performance in previous sessions. Each individual completed visual cognitive training exercises (Sandford, Browne, \&

TABLE 2. Treatment Decisions Used to Guide Electrode Placement and Type of Feedback

1) Electrode Placement-Start @ CZ and move to $C 3$ or $C 4$ as necessary

2) Protocol-Theta and SMR $\mathrm{mV}$ were used to guide decisions

If Theta is high then decrease theta @ CZ

If Theta is low then increase SMR @ CZ

If Pain or headache then increase SMR @ CZ

If Depression then increase alpha/beta @ C3

3) Coherence training (usually in $\mathrm{mTBI}$ and location based upon brain maps) was started with

a) frontal alpha and beta

b) short connections and move to longer connections

c) CZ, C3, and C4 and move forward then backward

4) Notes for coherence training

a) increase coherence is easier, while decrease coherence is more difficult

b) start coherence training after 5 or 6 sessions of unipolar training

5) Use the IVA to guide electrode placement

a) if VAQ is low, start at C4 (decrease theta or increase SMR) on visual tasks

b) if $A A Q$ is low, start at $C 3$ (decrease theta or increase SMR) on auditory tasks 
Turner, 1993) and auditory cognitive training exercises (Sandford \& Turner, 1996) on a separate computer at the same time as they received the auditory and visual EEG biofeedback. Most exercises on the visual tasks were presented for two minutes. Tasks could be repeated depending upon the person's performance and interest level. Other computer card games were used to promote problem solving, short-term memory, and attention. The cognitive retraining exercises were used to teach basic attention skills of inhibition, speed of responding, and consistency of responding visual cognitive training exercises (Sandford, Browne, \& Turner, 1993) and auditory cognitive training exercises (Sandford \& Turner, 1996). The goal of each session was to increase task accuracy with immediate feedback, increase dual processing (auditory and visual feedback) and present multiple tasks in which the individual could experience and understand their deficits and work to overcome the deficits as quickly as possible. Throughout treatment, the computer was used to teach inhibition of impulsivity and increase accuracy of responding on tasks that require a quick accurate response. During initial treatment sessions, accuracy of responding was stressed to increase inhibition and quick decisions on tasks. After accuracy was high, speed of responding with high accuracy was trained with many different tasks.

Test Instruments: The NIS is 72-item, self-report scale. It has 3 validity scales of Defensiveness, Affective, and Inconsistency, 3 summary scales of General Measurement of Impairment (GMI) (total of 5 symptom scales), Total Items Checked (TIC), and Symptom Intensity Measure (SIM) (Global Measure of Impairment/Total Items Checked), and 6 symptom scales of Critical Neurological Items, Cognitive Efficiency, Attention, Memory, Frustration Tolerance, Language-Verbal Learning, and Academic problems. Subjects were asked to rate the severity of problems described by items on a scale of $0=$ Not At All, 1 = A Little Bit, 2 = Moderately, $3=$ Quite A Bit, and $4=$ Extremely.

The WCST is a card sorting neuropsychological test in which the person must determine the underlying principles and change their responses accordingly based upon feedback. The WCST was presented and scored on a 386 IBM compatible computer. The IVA test was completed on a 386 IBM compatible computer. Subjects were seated in front of the VGA computer monitor about 37.5 to 60 centimeters away from the screen. The center of the monitor was an inch or two below eye level. An ergonomic two-button mouse was placed in front of the computer screen and the left button was used to record responses. The subject's arm was allowed to rest on the table in a comfortable position. The visual stimuli (one or two) were green in color, 3.75 centimeters high and presented for 167 milliseconds (ms) inside a rectangle positioned in the middle of the computer screen. The auditory stimuli (one or two) were presented with Sony model 30 headphones attached to an 8-bit Sound Blaster card and lasted for 500 milliseconds (ms). The rectangle on the computer 
screen was blank during auditory presentation. The response result of each stimulus was saved on the computer for analysis. During analysis, IVA raw score variables for subjects in the control, mTBI and ADHD groups were converted to standard scores $(\mathrm{M}=100$ and $\mathrm{SD}=15)$ based upon the normative data from the IVA.

Task instructions for the IVA were presented on the computer. In the warm-up part of the test, the subject was instructed by the voice on the computer to click the mouse when he or she saw a "1." Next, the subject was instructed by the voice on the computer to click the mouse when he or she heard a " 1 " for ten trials. For practice trials, the subjects were instructed and given a demonstration that they would see or hear a " 1 " or a " 2 ." They were instructed to click the mouse when they saw or heard a " 1 " (target) and not click the mouse when they saw or heard a " 2 " (error) for ten trials. In the main part of the test, RT was collected on five blocks of 100 trials (500 trials total) and lasted approximately thirteen minutes. Consistent with the warmup, each subject was instructed to click the mouse when they saw or heard a "1" (target) and not click the mouse when they saw or heard a "2" (error). During the first fifty trials of a one hundred trial block, the target was presented on forty-two of the trials (84\%) and the error on eight trials (16\%) for a target to error ratio of 5.25 to 1 . In the second fifty trials of the one hundred trial block, the target was presented on eight of the trials (16\%) and the error on forty-two trials (84\%) with a target to error ratio of 1 to 5.25. The presentation of visual and auditory stimuli were equally balanced in each one hundred trial block. After the five hundred trials, the cool-down part of the test was completed. This was identical to the warm-up previously described. The entire IVA test lasted about twenty minutes to complete instructions, warm-up, main test, and cool-down.

\section{RESULTS}

The correlations of change scores (Post-Treatment - Pre-Treatment) of the IVA Full Scale Attention Quotient (FSAQ) and NIS General Measure of Impairment (GMI) for the control $(\mathrm{r}=-.41), \mathrm{mTBI}(\mathrm{r}=.06)$ and ADHD $(\mathrm{r}=$ -.17 ) groups were not significant (all $p$ 's $>.05$ ). The correlation between change scores (Post-Treatment minus Pre-Treatment) of the IVA FSAQ and Full Scale Response Control Quotient (FSRQ), WAIS-R Full Scale Intelligence Quotient (FSIQ) and NIS GMI and demographic variables of number of sessions, days between testing, age, and education did not show a significant relationship among the groups (all $p$ 's > .05), and demographic variables were not included in further analysis. For groups of dependent variables, a Multivariate Analysis of Variance (MANOVA) mixed design was used for analysis with Group (Control, mTBI, ADHD) as a between subjects factor 
and Treatment (Pre, Post) as a within subjects factor. The multivariate Group by Treatment Interaction of the MANOVA described significant changes due to treatment in the dependent variables and significant univariate Group by Treatment Interactions. Post hoc comparisons with the Bonferroni T-test was used with an alpha level of $p<.05$.

The MANOVA for IVA summary scales of FSAQ, FSRQ, Hyperactivity, and Balance found a significant multivariate Group by Treatment Interaction ( $\mathrm{f}=2.77, \mathrm{df}=8,76, p=.01)$. The univariate analysis of FSAQ ( $\mathrm{f}=5.76, \mathrm{df}=$ $2,42, p<.006)$ and FSRQ ( $\mathrm{f}=6.40, \mathrm{df}=2,42, p<.004)$ were significant. For the FSAQ and FSRQ interactions shown in Table 3, post hoc Bonferroni T-test results found that at pre-treatment the mTBI and ADHD groups scored significantly less than the control group while at post-treatment there was no difference between groups. Further, the mTBI and ADHD groups showed significantly higher scores at post-treatment compared to pre-treatment, while the control group did not change. The MANOVA for IVA secondary scales of Auditory Attention Quotient (AAQ), Visual Attention Quotient (VAQ), Auditory Response Control Quotient (ARCQ), and Visual Response Control Quotient (VRCQ) found a significant Group by Treatment Interaction $(\mathrm{f}=2.09, \mathrm{df}=8,76, p<.04)$. The univariate analysis of AAQ $(\mathrm{f}=3.35$, $\mathrm{df}=2,42, p<.04)$, VAQ ( $\mathrm{f}=3.09$, df = 2, 42, $p<.05)$, ARCQ (f=6.29, df = $2,42, p<.004)$ and VRCQ $(\mathrm{f}=5.27, \mathrm{df}=2,42, p<.009)$ were significant. For the AAQ, ARCQ, and VRCQ interactions, post hoc Bonferroni T-test results shown in Table 3 found that at pre-treatment the mTBI and ADHD groups scored significantly less than the control group while at post-treatment there were no differences between groups. Further, the mTBI and ADHD groups showed significantly higher scores at post-treatment compared to pre-treatment while the control group did not change. For the VAQ interaction, post hoc Bonferroni T-test results shown in Table 3 found at pre-treatment the mTBI group scored significantly less than the control group while at post-treatment there were no differences between groups. Further, the mTBI and ADHD groups showed significantly higher scores at post-treatment compared to pre-treatment while the control group did not change. The MANOVA IVA individual scales of Auditory Vigilance, Visual Vigilance, Auditory Focus, Visual Focus, Auditory Speed, and Visual Speed found the multivariate Group by Treatment Interaction ( $\mathrm{f}=1.49$, $\mathrm{df}=12,72, p=.15$ ) was not significant. The MANOVA for IVA individual scales of Auditory Prudence, Visual Prudence, Auditory Consistency, Visual Consistency, Auditory Stamina, and Visual Stamina found the multivariate Group by Treatment Interaction ( $\mathrm{f}=2.61$, $\mathrm{df}=12,72, p<.006)$ was significant. The univariate analysis for Visual Prudence ( $\mathrm{f}=6.19, \mathrm{df}=2,42, p<.004$ ) and Auditory Consistency (f $=5.26, \mathrm{df}=2,42, p<.007$ ) were significant. For the Visual Prudence and Auditory Consistency interactions, post hoc Bonferroni T-test shown in Table 3 
TABLE 3. Means and Standard Deviations for the IVA Full, Secondary, Individual, and Validity Scales

\begin{tabular}{|c|c|c|c|}
\hline Variable & Control & $m T B I$ & $A D H D$ \\
\hline \multicolumn{4}{|c|}{ Full Scale Attention Quotient } \\
\hline Pre & $100.7(8.9)$ & $74.3(27.3)$ * & $80.1(20.7)$ * \\
\hline Post & $104.3(11.0)$ & $97.1(19.3)$ ** & $95.2(20.4)$ ** \\
\hline \multicolumn{4}{|c|}{ Full Scale Response Quotient } \\
\hline Pre & $117.6(8.3)$ & $91.2(19.9)$ * & $89.9(17.1)$ * \\
\hline Post & $112.2(12.4)$ & 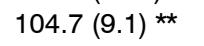 & $107.6(13.5)$ ** \\
\hline \multicolumn{4}{|c|}{ Auditory Attention Quotient } \\
\hline Pre & $102.0(9.3)$ & $75.7(27.6) *$ & $78.8(21.8)$ * \\
\hline Post & $104.8(10.6)$ & $94.7(13.4)$ ** & $93.5(20.7)$ ** \\
\hline \multicolumn{4}{|c|}{ Visual Attention Quotient } \\
\hline Pre & $98.7(13.1)$ & $77.0(29.5)$ * & $85.5(18.5)$ \\
\hline Post & $103.2(12.5)$ & $97.8(19.9)$ ** & $97.9(17.4)$ ** \\
\hline \multicolumn{4}{|c|}{ Auditory Response Control Quotient } \\
\hline Pre & $115.3(8.7)$ & $90.7(20.9)$ * & $88.9(11.1)$ * \\
\hline Post & $108.8(10.6)$ & $103.8(10.6)$ ** & $103.7(16.9)$ ** \\
\hline \multicolumn{4}{|c|}{ Visual Response Control Quotient } \\
\hline Pre & $117.1(11.0)$ & $93.2(14.6)$ * & $93.0(19.9)$ * \\
\hline Post & $113.5(14.8)$ & $106.9(10.4) * \star$ & $109.6(7.4)$ ** \\
\hline \multicolumn{4}{|c|}{ Prudence Auditory } \\
\hline Pre & $107.0(6.5)$ & $91.7(23.8)$ & $92.5(18.6)$ \\
\hline Post & $105.7(9.1)$ & $103.1(10.2)$ & $98.4(19.2)$ \\
\hline \multicolumn{4}{|l|}{ Visual } \\
\hline Pre & $105.3(6.9)$ & $91.5(15.9)$ * & $84.2(19.2)$ * \\
\hline Post & $106.5(8.4)$ & $100.7(14.3)$ ** & $106.8(7.4)$ ** \\
\hline \multicolumn{4}{|c|}{ Consistency Auditory } \\
\hline Pre & $111.5(10.7)$ & $87.5(18.3)$ * & $89.8(11.5)$ * \\
\hline Post & $108.0(10.8)$ & $97.6(12.0)$ ** & $104.7(14.2)$ ** \\
\hline \multicolumn{4}{|l|}{ Visual } \\
\hline Pre & $115.2(17.7)$ & $98.7(12.9)$ & $104.1(14.9)$ \\
\hline Post & 116.1 (16.2) & $111.6(13.5)$ & $114.5(9.9)$ \\
\hline \multicolumn{4}{|c|}{ Comprehension Auditory } \\
\hline Pre & $105.7(6.9)$ & $72.8(38.7)$ * & $86.2(35.5)$ \\
\hline Post & $103.1(11.9)$ & $103.0(10.2) * \star$ & $105.7(3.3)$ \\
\hline \multicolumn{4}{|l|}{ Visual } \\
\hline Pre & $106.7(4.1)$ & $70.2(39.8)$ * & $82.6(38.3)$ \\
\hline Post & $103.2(7.7)$ & $106.8(4.7) \star \star$ & $95.2(26.2)$ \\
\hline
\end{tabular}


results found the mTBI and ADHD groups scored significantly less than the control group at pre-treatment, while at post-treatment there were no differences between groups. Further, the mTBI and ADHD groups showed significantly higher scores at post-treatment compared to pre-treatment while the control group did not change. The MANOVA for IVA validity scales of Auditory Readiness, Visual Readiness, Auditory Comprehension, Visual Comprehension, Auditory Sensory/Motor, Visual Sensory/Motor, Auditory persistence, and Visual persistence found the multivariate Group by Treatment Interaction was significant $(\mathrm{f}=1.77 \mathrm{df}=16,68, p<.05)$. The univariate analysis for Auditory Comprehension ( $\mathrm{f}=4.89$, $\mathrm{df}=2,42, p<.01)$ and Visual Comprehension ( $\mathrm{f}=7.10, \mathrm{df}=2,42, p<.002$ ) were significant. For Auditory Comprehension and Visual Comprehension interactions, post hoc Bonferroni T-test shown in Table 3 results found the mTBI group scored significantly less than the control group at pre-treatment, while at post-treatment there were no differences between groups. Further, the mTBI group showed significantly higher scores at post-treatment compared to pre-treatment while the control or ADHD groups did not change.

The MANOVA for NIS validity scales (Defensiveness, Affective, Inconsistency) and summary scales (Global Measure of Impairment, Total Items Checked (TIC), and Symptom Intensity Measure) found a significant multivariate Group by Treatment Interaction ( $\mathrm{f}=3.29$, $\mathrm{df}=12,68, p=.001)$. The univariate analysis found a significant interaction for Inconsistency ( $\mathrm{f}=18.7$, df $=2,40, p<.008)$, General Measure of Impairment ( $\mathrm{f}=4.73, \mathrm{df}=2,40, p<$ $.01)$, and Total Items Checked $(\mathrm{f}=4.78, \mathrm{df}=2,40, p<.01)$. For the Inconsistency interaction, post hoc Bonferroni T-test results shown in Table 4 found the mTBI group had significantly higher scores than the control group at pre-treatment while at post-treatment there was no difference between groups. Further, the mTBI and ADHD groups scored significantly less at post-treatment compared to pre-treatment while the control group did not change. For the GMI interaction, post hoc Bonferroni T-test results found the mTBI and ADHD groups rated more symptoms than the control group at pre-treatment while at post-treatment only the mTBI group rated more symptoms than the control group. Further, the mTBI and ADHD groups scored significantly less at post-treatment compared to pre-treatment while the control group did not change. For the TIC interaction, post hoc Bonferroni T-test results found the mTBI and ADHD groups checked more symptoms than the control group at pre-treatment while at post-treatment only the mTBI group checked more symptoms than the control group. Further, the mTBI and ADHD groups scored significantly less at post-treatment compared to pre-treatment while the control group did not change.

The MANOVA for NIS symptom scales (Critical Neurological Items, Cognitive Efficiency, Attention, Memory, Frustration Tolerance, Language- 
Verbal Learning, and Academic) found the multivariate Group by Treatment Interaction ( $\mathrm{f}=1.91, \mathrm{df}=14,66, p=.04)$ was significant. The univariate analysis found a significant interaction for Attention ( $\mathrm{f}=3.52, \mathrm{df}=2,40, p<$ .03 ), Language/Verbal Learning ( $\mathrm{f}=6.12, \mathrm{df}=2,40, p<.005)$, and Academic Problems $(\mathrm{f}=4.79, \mathrm{df}=2,40, p<.01)$. For the Attention and Academic Problems interactions, post hoc Bonferroni T-test results shown in Table 4 found the mTBI and ADHD groups rated more symptoms than the control group at pre-treatment while at post-treatment only the mTBI group rated more symptoms than the control group. Further, the mTBI and ADHD groups rated significantly fewer symptoms at post-treatment compared to pre-treatment while the control group did not change. For the Language/Verbal Learning interaction, post hoc Bonferroni T-test results shown in Table 4 found the mTBI and ADHD groups rated more symptoms than the control group at

TABLE 4. Means and Standard Deviations for the Neuropsychological Impairment Summary and Symptom Scales

\begin{tabular}{|c|c|c|c|}
\hline Variable & Control & $m T B I$ & $A D H D$ \\
\hline \multicolumn{4}{|c|}{ Inconsistency } \\
\hline Pre & $3.7(2.6)$ & $7.9(3.6)$ * & $6.3(2.1)$ \\
\hline Post & $3.8(2.8)$ & $5.0(2.3)$ ** & $4.0(2.0)^{\star \star}$ \\
\hline \multicolumn{4}{|c|}{ General Measure of Impairment } \\
\hline Pre & $46.7(30.8)$ & $147.0(44.9)$ * & $117.6(38.8)$ * \\
\hline Post & $44.1(29.0)$ & $107.6(57.6) * \star$ & $84.6(68.6)$ ** \\
\hline \multicolumn{4}{|c|}{ Total Items Checked } \\
\hline Pre & $31.1(16.6)$ & $60.7(10.0) *$ & $56.7(11.4) *$ \\
\hline Post & $32.9(19.3)$ & $53.7(15.4)$ ** & $45.8(15.7)$ ** \\
\hline \multicolumn{4}{|l|}{ Attention } \\
\hline Pre & $8.7(7.5)$ & $22.4(6.8) *$ & $19.3(8.2)$ * \\
\hline Post & $7.5(6.2)$ & $15.8(8.4) * \star$ & $13.7(10.5) * *$ \\
\hline \multicolumn{4}{|c|}{ Language-Verbal Learning } \\
\hline Pre & $2.7(2.6)$ & $12.9(4.9)$ * & $7.8(5.1)$ * \\
\hline Post & $3.5(2.8)$ & $8.4(6.2)$ ** & $6.3(5.6)$ \\
\hline \multicolumn{4}{|c|}{ Academic Problems } \\
\hline Pre & $6.4(4.3)$ & $18.8(7.0)$ * & $22.9(4.7)$ * \\
\hline Post & $7.7(5.2)$ & $18.6(16.3) * \star$ & $13.9(7.7)$ ** \\
\hline \multicolumn{4}{|c|}{$\begin{array}{l}\text { * Significantly Different from Pre-Treatment Control } \\
\text { * Significantly Different from Pre-Treatment Score }\end{array}$} \\
\hline
\end{tabular}


pre-treatment while at post-treatment only the mTBI group rated more symptoms than the control group. Further, only the mTBI rated significantly fewer symptoms at post-treatment compared to pre-treatment while the control group did not change.

The MANOVA for WAIS-R Full Scale IQ, Verbal IQ, and Performance IQ found the Group by Treatment Interaction ( $\mathrm{f}=2.73$, $\mathrm{df}=6,54, p<.02$ ) was significant. The univariate analysis for FSIQ ( $\mathrm{f}=2.72, \mathrm{df}=2,30, p<.08$ ), VIQ $(\mathrm{f}<1)$ and PIQ ( $\mathrm{f}=2.50, \mathrm{df}=2,30, p<.09)$ were not significant. The MANOVA for WCST Number of Trials, Errors, Perseverative Errors, and Nonperseverative Errors found the multivariate Group by Treatment Interaction ( $\mathrm{f}=2.47$, $\mathrm{df}=8,66, p=.02$ ) was significant. The univariate analysis found a significant interaction for Number of Trials $(\mathrm{f}=3.99, \mathrm{df}=1,37, p<$ .02 ) and Number of Perseverative Errors ( $\mathrm{f}=4.17 \mathrm{df}=1,37, p<.02$ ). For the Number of Trials and Number of Perseverative Errors interactions, post hoc Bonferroni T-test shown in Table 5 results found the mTBI group had higher scores than the control group at pre-treatment while at post-treatment the mTBI group was not significantly different from the control group. Further, the mTBI group scored significantly less at post-treatment compared to pre-treatment while the control and ADHD groups did not change.

\section{DISCUSSION}

The treatment model of simultaneously providing EEG biofeedback (neurotherapy) and cognitive retraining exercises significantly improved scores on a measure of sustained attention in individuals diagnosed with mTBI and ADHD when compared to a normal control group that did not receive treat-

TABLE 5. Means and Standard Deviations for the Wisconsin Card Sorting Test

\begin{tabular}{|lccc|}
\hline Variable & Control & $m T B I$ & ADHD \\
Number of Trials & & & \\
$\quad$ Pre & $85.9(16.9)$ & $107.9(21.6) *$ & $99.2(16.3)$ \\
Post & $88.5(19.1)$ & $89.0(18.7) * \star$ & $88.5(13.9)$ \\
& & & \\
Perseverative Errors & & & $10.9(3.8)$ \\
$\quad$ Pre & $8.5(6.4)$ & $22.6(19.9) *$ & $10.6(7.7)$ \\
Post & $7.8(5.4)$ & $10.4(9.2) * *$ & \\
* Significantly Different from Pre-Treatment Control & & \\
** Significantly Different from Pre-Treatment Score & & \\
\hline
\end{tabular}


ment. Full scale sustained attention (FSAQ) and full scale response accuracy (FSRQ) of the IVA CPT was significantly less than the mTBI and ADHD groups at pre-treatment, but at post-treatment was in the normal range. The IVA secondary scales showed significant improvement after treatment for the mTBI and ADHD groups suggesting that auditory and visual modalities improve equally from treatment. The treatment effect was similar in the mTBI and ADHD groups on auditory and visual attention response accuracy scales in that both groups show a similar improvement in test scores at post-treatment. Test experience to complete the IVA and NIS and time between testing did not account for the treatment effect on sustained attention or self report of symptoms for the mTBI and ADHD groups. The changes from treatment in this model were not related to age or education. In regard to neuropsychological tests, the results of the WCST suggest that tasks related to frontal lobe functioning may be an outcome measure for treatment with EEG biofeedback or neurotherapy at least for the mTBI group. There was no significant change in intelligence scores on the WAIS-R from treatment as all three groups showed a practice effect. Intelligence scores may not be an adequate measure of change for this treatment model because of a practice effect.

The individual IVA attention scales (Speed (RT), focus and vigilance) showed improvement after treatment but did not reach the level of significance. A specific individual attention scale could not account for the change in full scale and secondary scale attention, but the sum of the individual attention scales contributed to significant changes in the full and secondary scales. Individual response accuracy scales showed a decrease in visual impulsivity and an increase in auditory consistency for the mTBI and ADHD groups. The remaining individual response accuracy scales did not reach the level of significance, but contributed to the significant change in response accuracy on full and secondary scales. Another change in accuracy of responding was found on the comprehension scale of the IVA. For the mTBI group, auditory and visual comprehension scales found a significant decrease in multiple clicks and fine motor movement with the mouse during the test. At post-treatment the mTBI group but not the ADHD group showed significantly less fine motor movement and greater ability to tolerate boring tasks as a result of treatment, however the mTBI group started out lower than the ADHD group and there was more room for improvement to post-treatment scores.

The change scores (Post-Treatment minus Pre-Treatment) of the NIS GMI self-report scale and the IVA FSAQ or FSRQ scales were not correlated in each group. The NIS is a self report of symptoms over a wide range of situations and areas of functioning that includes personal perception and bias. At pre-treatment, the mTBI and ADHD groups scored higher than the control 
on the Inconsistency scale of the NIS, but at post-treatment all groups were similar suggesting a significantly greater consistency in self awareness of symptoms as a result of treatment. The control group showed no change on the NIS scales but the mTBI and ADHD groups showed a significant decrease in symptoms at post-treatment. The NIS items measure a self report of many situations and the decrease in scores is probably an attempt by individuals in treatment groups to generalize changes from the sessions in the office to other situations. The mTBI group scored higher on several of the NIS scales than the control group at post-treatment, while the ADHD group scored the same as the control group. The developmental and long term problems for persons in the ADHD group compared to the sudden changes for the mTBI group may allow the ADHD group to generalize the changes faster and in more situations resulting in scores that are similar to the control group at post-treatment. On the WCST, problem solving and concept formation in the mTBI group were significantly different from the control group prior to treatment and therefore, the mTBI group may take more time or trials to generalize the results of treatment.

The results suggest that EEG biofeedback and cognitive retraining maybe a viable alternative treatment option to medication for adults with mTBI and ADHD. Rossiter and La Vaque (1995) suggested that EEG biofeedback may be the treatment of choice in cases where medication is ineffective, only partially effective, has unacceptable side effects, or where compliance with taking medication is low in children with ADHD. The present results suggest a similar conclusion in regard to treatment with EEG biofeedback and cognitive retraining in adults with ADHD or mTBI. There are few reports published on the efficacy of medication with mTBI (Levin, 1991; Lozano, 1991; Maldonado, Perez \& Escario, 1991; Spiers \& Hochanadel, 1999). However, methylphenidate showed a significant decrease in symptoms with ADHD (Gualtieri, Ondrusek, \& Finley, 1985; Mattes, Boswell, \& Oliver, 1984). A typical psychotherapy treatment plan promotes coping skills for ADHD and mTBI. The treatment plan does not change sustained attention. A goal of this treatment model was to increase functional performance and decrease symptoms in twenty sessions or less. Previously, significant changes were shown in children with ADHD after twenty sessions (Rossiter \& La Vaque, 1995). This treatment model showed functional changes in attention and self reports of symptoms. The relationship between these changes and changes in quantitative EEG are unknown. The results are limited in the ability to define the curative aspects, parts or exercises in the mTBI and ADHD groups. Norris (1995) suggested that EEG biofeedback is one tool in treatment and may not solely account for all treatment changes. It is possible that some individuals in the treatment groups responded to the EEG biofeedback, others to the cognitive retraining, and some to the combination of both methods. A design 
where an individual would receive randomly or inconsistent feedback would help to assess for changes due to the relationship of the therapist. Further research comparing EEG biofeedback and cognitive retraining would be helpful to describe which elements of treatment are most beneficial in treatment groups. Outcome research of long-term changes from treatment is also needed.

\section{REFERENCES}

American Psychiatric Association. (1994). Diagnostic and Statistical Manual of Mental Disorders (4th ed.). Washington, DC: Author.

Ayers, M. (1993). A controlled study of EEG neurofeedback training and clinical psychotherapy for right hemisphere closed head injury, Biofeedback and Self Regulation, 18 (3), 10-15.

Byers, A. P. (1995). Neurofeedback therapy for a mild head injury, Journal of Neurotherapy, 1(1), 22-37.

Gasquoine, P. G. (1997). Post concussion symptoms, Neuropsychology Review, 7(2), 77-85.

Gentilini, M., Nichelli, P., \& Schoenhuber, R. (1989). Assessment of attention in mild head injury. In Levin, H. S., Eisenberg, H. M., \& Benton, A.L. (Eds.), (pp. 163-175). Mild Head Injury. New York: Oxford University Press.

Gualtieri, C., Ondrusek, G., \& Finley, C. (1985). Attention deficit disorder in adults, Clinical Neuropharmacology, 8, 343-356.

Gronwall, D. (1989). Cumulative and persisting effects of concussion on attention and cognition. In Levin, H. S., Eisenberg, H. M., \& Benton, A.L. (Eds.), (pp. 153-162). Mild Head Injury. New York: Oxford University Press.

Gronwall, D. \& Sampson H. (1974). The Psychological Effects of Concussion. Auckland, NZ: Auckland University Press.

Heaton, R. K., Chelune, G. J., Talley, J. L., Kay, G. G., \& Curtiss, G. (1993). Wisconsin Card Sorting Test: Revised and Expanded, Odessa, FL: Psychological Assessment Resources, Inc. (Manual).

Levin, H. S. (1991). Treatment of postconcussion symptoms with CDP-choline, Journal of Neurological Sciences, 103, S39-S42.

Lozano, R. (1991). CDP-choline in the treatment of crania-cephalic trauma, Journal of Neurological Sciences, 103, S43-S47.

Lezak, M. D., (1995). Neuropsychological Assessment (3rd ed.). New York: Oxford University Press.

Lubar, J. O. \& Lubar, J. F. (1984). Electroencephalographic biofeedback of SMR and beta for treatment of attention deficit disorder, Biofeedback and Self Regulation, 9(1), 1-23.

Maldonado, V. C., Perez, J. B. C. \& Escario, J. A. (1991). Effects of CDP-choline on the recovery of patients with head injury, Journal of Neurological Sciences, 103, S15-S18.

Mann, C. A., Lubar, J. R., Zimmerman, A. W., Miller, C. A. \& Muenchen, R. A. (1990). Quantitative analysis of EEG in boys with attention-deficit-disorder: Controlled study with clinical implications, Pediatric Neurology, 8(1), 30-36. 
Mattes, J., Boswell, L., \& Oliver, H. (1984). Methylphenidate effects on symptoms of attention disorder in adults, Archives of General Psychiatry, 41, 1059-1063.

Mild Traumatic Brain Injury Committee of the Head Injury Interdisciplinary Special Interest Group of the American College of Rehabilitation Medicine. (1993). Definition of mild traumatic brain injury, Journal of Head Trauma Rehabilitation, 8, 86-87.

Norris, S. L. (1995). Neurofeedback: One instrument in the orchestra, Journal of Neurotherapy, 1 (2), 74-76.

O’Donnell, W. E., DeSoto, C. B., DeSoto, J. L., \& Reynolds, D. McQ. (1984). Neuropsychological Impairment Scales (NIS) Manual. Annapolis, MD: Annapolis Neuropsychological Services.

Rossiter, T. R. \& La Vaque, T. J. (1995). A comparison of EEG biofeedback and psychostimulants in treating attention, Journal of Neurotherapy, 1 (1), 48-59.

Sandford, J. A., Browne, R. J., \& Turner, A. (1993). Captain's Log Cognitive Training System (Computer Program). Richmond, VA: Braintrain Inc.

Sandford, J. A. \& Turner, A. (1996). Alphabet Bingo (Computer Program). Richmond, VA: Braintrain, Inc.

Sandford, J. A. \& Turner, A. (1995). Intermediate Visual and Auditory Continuous Performance Test. Richmond, VA: Braintrain, Inc.

Spiers, P. A. \& Hochanadel, G. (1999). Citicoline for traumatic brain injury: Report of two cases, including my own, Journal of International Neuropsychological Society, 5(3), 260-264.

Thatcher, R. (1987). Normative EEG database, Personal Communication, Copyright 1987.

Thatcher, R., Walker, R. Gerson, I., Geisler, F. (1989). EEG: Discriminate analysis of mild head trauma, Electroencephalography and Clinical Neurophysiology, 73, 94-106.

Tinius, T. P. (2000). The Intermediate Visual and Auditory Continuous Performance Test as a Neuropsychological Measure, Unpublished Manuscript.

Weschler, D. (1981). Wechsler Adult Intelligence Scale-Revised. New York: Psychological Corporation.

RECEIVED: $10 / 07 / 99$

REVISED: 03/01/00

ACCEPTED: 03/15/00 


\section{APPENDIX}

\section{Electrode Placement and Feedback Provided to Participants}

\begin{tabular}{|c|c|c|c|c|c|c|c|}
\hline \multicolumn{2}{|c|}{ Participant } & \multirow{2}{*}{$\frac{\mathrm{mTBI}-1}{\mathrm{IS} @ \mathrm{CZ}}$} & \multirow{2}{*}{$\frac{\text { mTBI-2 }}{\text { IAC@F4-T6 }}$} & \multirow{2}{*}{$\begin{array}{l}\text { mTBI-3 } \\
\text { IS@CZ }\end{array}$} & \multirow{2}{*}{$\begin{array}{l}\text { mTBI-4 } \\
\text { IS@CZ }\end{array}$} & \multirow{2}{*}{$\frac{\text { mTBI-5 }}{\text { IAC@F1-T3 }}$} & \multirow{2}{*}{$\frac{\mathrm{mTBI}-6}{\mathrm{IS} @ \mathrm{CZ}}$} \\
\hline & 1 & & & & & & \\
\hline$S$ & 2 & IS@CZ & IAC@F4-T6 & IB@CZ & IS@CZ & IAC@F1-T & IS@CZ \\
\hline $\mathrm{E}$ & 3 & IS@CZ & IAC@F4-T6 & IS@CZ & IS@CZ & IAC@F7-T5 & IS@CZ \\
\hline S & 4 & IS@CZ & IAC@F4-T6 & IS@CZ & IS@CZ & IAC@F7-T5 & IS@CZ \\
\hline S & 5 & IA@01 & IAC@F4-T6 & IS@CZ & IBC@F7-C3 & IS@CZ & IS@CZ \\
\hline I & 6 & IAC@F3-T5 & IAC@F4-T6 & IS@CZ & IBC@F7-C3 & IS@CZ & IS@CZ \\
\hline 0 & 7 & IS@ CZ & IAC@F4-T6 & IS@CZ & IBC@F7-C3 & IS@CZ & IS@CZ \\
\hline \multirow[t]{2}{*}{$\mathrm{N}$} & 8 & IS@CZ & IAC@F4-T6 & IAC@C4-F4 & IBC@F7-C3 & IS@CZ & IS@CZ \\
\hline & 9 & IS@ CZ & IAC@F4-T6 & IAC@T5-F3 & IBC@F7-C3 & IS@CZ & IS@CZ \\
\hline$N$ & 10 & IS@ CZ & IAC@F4-T6 & IAC@F3-C3 & IBC@F3-F7 & IS@CZ & IS@CZ \\
\hline U & 11 & IAC@F3-T5 & DBC@F7-T5 & IAC@F3-T5 & IBC@F3-F7 & IAC@F7-T5 & IS@CZ \\
\hline M & 12 & IAC@F3-T5 & DBC@F7-T5 & DT@T4 & IBC@F3-F7 & IAC@F7-T5 & IS@CZ \\
\hline B & 13 & IAC@F3-T5 & IS@CZ & DT@T4 & DTC@F7-O1 & IAC@F7-T5 & IS@CZ \\
\hline$E$ & 14 & IAC@F3-T5 & IS@CZ & IB@C3 & DTC@F7-O1 & IA@01 & IS@CZ \\
\hline \multirow[t]{6}{*}{$R$} & 15 & IAC@F3-T5 & IAC@F8-O2 & IB@C4 & DTC@F7-O1 & IAC@F1-T3 & DT@CZ \\
\hline & 16 & IAC@F3-T3 & IAC@F8-O2 & IB@C3 & DT@F7-T5 & IAC@F1-T3 & IS@CZ \\
\hline & 17 & IAC@F3-T3 & IAC@F8-O2 & & DT@F7-T5 & IAC@F1-T3 & IB@T4 \\
\hline & 18 & IAC@F3-T3 & IAC@F2-O2 & & DT@F7-T5 & IAC@F1-T3 & IB@T4 \\
\hline & 19 & IAC@F3-T3 & IAC@F2-O2 & & DT@F7-T5 & IAC@F1-T3 & IB@T3 \\
\hline & 20 & IAC@T3-T5 & IAC@F2-O2 & & DTC@T3-T5 & IAC@F1-T3 & IB@T3 \\
\hline \multicolumn{2}{|c|}{ Participant } & mTBI-7 & mTBI-8 & mTBI-9 & mTBI-10 & mTBI-11 & mTBI-12 \\
\hline & 1 & IS@CZ & IS@CZ & IB@F4 & IS@CZ & IS@CZ & IS@CZ \\
\hline S & 2 & IS@CZ & IS@CZ & IB@F4 & IS@CZ & IS@CZ & IS@CZ \\
\hline$E$ & 3 & IS@CZ & IS@CZ & IB@F4 & IS@CZ & IS@CZ & IS@CZ \\
\hline S & 4 & IS@CZ & IS@CZ & IB@F4 & IAC@F7-P3 & IBC@C4-F4 & IS@CZ \\
\hline S & 5 & DT@C3 & IS@CZ & IB@F4 & IAC@F7-P3 & IB@C3 & IS@C4 \\
\hline I & 6 & DT@CZ & IS@CZ & IB@F4 & IBC@F4-P4 & IB@C4 & IS@C3 \\
\hline $\mathrm{O}$ & 7 & IB@C3 & IBC@F4-F8 & IB@F4 & IAC@F7-P3 & IB@C3 & IB@C3 \\
\hline \multirow[t]{2}{*}{$N$} & 8 & IB@C3 & BC@F4-F8 & IB@F4 & IAC@F7-P3 & DB@T6 & IB@C3 \\
\hline & 9 & IB@C3-P3 & IBC@T4-F8 & IB@F4 & IAC@F8-T4 & IB@CZ & IBC@F4-T4 \\
\hline$N$ & 10 & IB@C3 & IBC@T4-F8 & IB@F4 & IAC@F4-C4 & IB@CZ & IBC@F4-T4 \\
\hline U & 11 & IB@C4 & IB@T4-F8 & IB@P4 & IS@CZ & IB@C4 & IAC@F4-P4 \\
\hline M & 12 & IB@C4 & IB@F4-F8 & IB@P4 & DD@CZ & IB@C4 & IAC@F4-P4 \\
\hline B & 13 & IB@C4 & IBC@F2-F4 & IB@P3 & DD@CZ & IB@C4 & IAC@F4-P4 \\
\hline$E$ & 14 & IB@C4 & IBC@F2-F4 & IB@P4 & DD@CZ & IB@C4 & IAC@F4-P4 \\
\hline \multirow[t]{6}{*}{$R$} & 15 & DT@T6 & IBC@F7-F3 & IB@P4 & DD@CZ & IB@C4 & IAC@T4-F8 \\
\hline & 16 & DT@C4 & IBC@F7-F3 & IB@P4 & DTC@C4-T4 & IB@C3 & IAC@T4-F4 \\
\hline & 17 & DT@T6 & IBC@F7-F3 & IB@P4 & DTC@C4-T4 & IB@C4 & IAC@T4-F4 \\
\hline & 18 & DT@C4 & IBC@C3-F7 & IB@P4 & DTC@C4-T4 & IB@C4 & IAC@C3-01 \\
\hline & 19 & DT@C4 & ITC@C4-T6 & IB@P4 & IS@CZ & IB@C4 & IAC@C3-O1 \\
\hline & 20 & IB@C3 & ITC@C4-T6 & IB@F3 & IS@CZ & IA@02 & IAC@C3-O1 \\
\hline
\end{tabular}




\begin{tabular}{|c|c|c|c|c|c|c|c|}
\hline \multicolumn{2}{|c|}{ Participant } & \multirow{2}{*}{$\frac{\text { mTBI-13 }}{\text { DDC@T3-O1 }}$} & \multirow{2}{*}{$\frac{\text { mTBI-14 }}{\text { DAC@P3-O1 }}$} & \multirow{2}{*}{$\frac{\mathrm{mTBI}-15}{\mathrm{IS} @ \mathrm{CZ}}$} & \multirow{2}{*}{$\frac{\mathrm{mTBI}-16}{\mathrm{IS} @ \mathrm{CZ}}$} & \multirow{2}{*}{$\frac{\text { ADHD-1 }}{\text { IS@CZ }}$} & \multirow{2}{*}{$\frac{\text { ADHD-2 }}{\text { DT@CZ }}$} \\
\hline & 1 & & & & & & \\
\hline s & 2 & DDC@T3-O1 & DAC@P3-O1 & IS@CZ & IS@CZ & IS@CZ & IS@CZ \\
\hline $\mathrm{E}$ & 3 & IS@CZ & DAC@P3-O & IS@CZ & IS@CZ & IB@F3 & IS@CZ \\
\hline S & 4 & IS@CZ & DAC@P3-O1 & IS@CZ & IS@CZ & IB@F3 & IS@CZ \\
\hline S & 5 & IS@CZ & IB@C3 & DT@CZ & DT@CZ & IB@C4 & IS@CZ \\
\hline 1 & 6 & IS@CZ & IB@C3 & DT@T5 & DT@T5 & IB@C4 & IAC@C4-T4 \\
\hline $\mathrm{O}$ & 7 & IS@CZ & IB@C3 & DT@T5 & DT@T5 & IB@C3 & IAC@C4-T4 \\
\hline \multirow[t]{2}{*}{ N } & 8 & IS@CZ & IB@C3 & DT@T5 & DT@T5 & IB@C3 & DAC@C4-T4 \\
\hline & 9 & IS@CZ & IB@C3 & IS@F3-T5 & IAC@F3-T5 & IB@C3 & IB@C4 \\
\hline $\mathrm{N}$ & 10 & IS@CZ & DB@F8 & IS@F3-T5 & IAC@F3-T5 & IB@C3 & IA@T6 \\
\hline U & 11 & IS@CZ & DBC@F8-T4 & IAC@F2-T4 & IAC@T5-F1 & IB@C3 & DT@01 \\
\hline M & 12 & IS@CZ & DBC@F8-T4 & IAC@F2-T4 & DT@P3 & IB@T4 & DAC@C4-T4 \\
\hline B & 13 & IS@CZ & DBC@F8-T4 & IAC@F8-T4 & DT@P3 & IB@T4 & DAC@C4-T4 \\
\hline$E$ & 14 & IS@CZ & DAC@P3-O1 & IAC@F8-T4 & DT@F3 & IB@C4 & DTC@C4-T4 \\
\hline \multirow[t]{6}{*}{$\mathrm{R}$} & 15 & DDC@T3-O1 & DAC@P3-O1 & IAC@F8-T4 & DT@F3 & IB@F4 & DTC@C4-T4 \\
\hline & 16 & DDC@T3-O1 & DB@O1 & IAC@F4-T4 & DT@P3 & IBC@F3-F7 & DTC@P4-T6 \\
\hline & 17 & IS@CZ & DBC@C3-01 & ITC@C4-T6 & IAC@C3-T5 & IBC@F4-F8 & IB@C4 \\
\hline & 18 & IS@CZ & DBC@C3-01 & ITC@C4-T6 & IS@F3 & IBC@F4-F8 & IB@C3 \\
\hline & 19 & IS@CZ & DAC@T3-T5 & ITC@C4-T6 & DT@F3 & IBC@F4-F8 & IB@C4 \\
\hline & 20 & IS@CZ & DB@01 & ITC@C4-T6 & DT@F3 & IBC@F4-F8 & IB@C3 \\
\hline \multicolumn{2}{|c|}{ Participant } & ADHD-3 & ADHD-4 & ADHD-5 & ADHD-6 & ADHD-7 & ADHD-8 \\
\hline & 1 & IS@CZ & IS@CZ & IS@CZ & IS@CZ & IS@CZ & DT@CZ \\
\hline S & 2 & IS@CZ & IS@CZ & IS@CZ & IS@CZ & DT@CZ & DT@CZ \\
\hline $\mathrm{E}$ & 3 & DT@CZ & IS@CZ & DT@CZ & IS@CZ & DT@CZ & DT@CZ \\
\hline S & 4 & DT@CZ & IS@C4 & DT@CZ & IS@CZ & DT@F4 & DT@CZ \\
\hline S & 5 & DT@CZ & IS@C4 & DT@CZ & IS@CZ & DT@F4 & DT@CZ \\
\hline I & 6 & DTC@P4-O2 & IS@C4 & DT@CZ & IB@CZ & DT@F4 & DT@CZ \\
\hline $\mathrm{O}$ & 7 & DTC@P4@O2 & IS@C4 & IS@CZ & IB@C3 & DT@F4 & DT@CZ \\
\hline \multirow[t]{2}{*}{ N } & 8 & DTC@P4@02 & IS@CZ & DT@CZ & IB@C3 & IB@C3 & DT@CZ \\
\hline & 9 & DTC@P2-O2 & IS@C4 & DT@CZ & IB@C3 & IB@C3 & DT@CZ \\
\hline $\mathrm{N}$ & 10 & DBC@P3-P4 & IS@C3 & DT@CZ & IB@C3 & IB@C3 & DT@CZ \\
\hline U & 11 & IS@CZ & IB@C3 & DT@CZ & & IS@CZ & DT@CZ \\
\hline M & 12 & IS@CZ & IB@C3 & DT@CZ & & IS@CZ & DT@CZ \\
\hline B & 13 & IS@CZ & IB@C3 & DT@CZ & & IS@CZ & DTC@P4-T6 \\
\hline$E$ & 14 & & IB@C3 & DT@CZ & & DT@F4 & DTC@P4-T6 \\
\hline \multirow[t]{6}{*}{$\mathrm{R}$} & 15 & & IB@C4 & DT@CZ & & IA@02 & DT@P4 \\
\hline & 16 & & & IS@C3 & & IA@02 & DB@T6 \\
\hline & 17 & & & DT@C2 & & IS@CZ & DB@T6 \\
\hline & 18 & & & DT@C3 & & IS@CZ & DB@T6 \\
\hline & 19 & & & IB@C3 & & IB@P3 & DB@T6 \\
\hline & 20 & & & IB@C3 & & IB@P3 & DB@T6 \\
\hline
\end{tabular}


APPENDIX (continued)

\begin{tabular}{|c|c|c|c|c|c|c|}
\hline \multicolumn{2}{|c|}{ Participant } & \multirow{2}{*}{$\frac{\text { ADHD-9 }}{\text { IS@CZ }}$} & \multirow{2}{*}{$\frac{\text { ADHD-10 }}{\text { IS@CZ }}$} & \multirow{2}{*}{$\frac{\text { ADHD-11 }}{\text { IS@CZ }}$} & \multirow{2}{*}{$\frac{\text { ADHD-12 }}{\text { IS@CZ }}$} & \multirow{2}{*}{$\frac{\text { ADHD-13 }}{\text { IS@CZ }}$} \\
\hline & 1 & & & & & \\
\hline$S$ & 2 & IS@CZ & IS@CZ & IS@CZ & DT@CZ & IS@CZ \\
\hline$E$ & 3 & IS@CZ & IS@CZ & IS@CZ & DT@CZ & IS@CZ \\
\hline S & 4 & IS@CZ & IS@CZ & IAC@F3-C3 & DT@CZ & DT@CZ \\
\hline S & 5 & IS@CZ & IS@CZ & IAC@F3-O1 & DT@CZ & DT@CZ \\
\hline I & 6 & IS@CZ & ITC@P3-O1 & IAC@F3-O1 & DT@CZ & DT@CZ \\
\hline $\mathrm{O}$ & 7 & IB@C3 & DT@F3 & IAC@F3-O1 & DT@CZ & DT@CZ \\
\hline \multirow[t]{2}{*}{$N$} & 8 & IB@C3 & IAC@P3-O1 & IAC@F3-O1 & DT@CZ & DT@CZ \\
\hline & 9 & IB@C3 & IAC@F4-C4 & IAC@F3-O1 & DT@CZ & DT@CZ \\
\hline$N$ & 10 & IB@C4 & IAC@F4-O2 & IAC@F3-O1 & DT@CZ & DT@CZ \\
\hline U & 11 & IB@C4 & IAC@F4-O2 & IAC@F3-O1 & DB@C3 & IAC@F4-T4 \\
\hline M & 12 & IB@C4 & IAC@F4-O2 & IAC@F4-O2 & DB@C3 & IAC@F4-T4 \\
\hline B & 13 & IB@C4 & DT@C4 & IAC@F4-O2 & DB@C3 & IAC@F4-T4 \\
\hline$E$ & 14 & IB@C4 & DT@C4 & IAC@F4-O2 & IA@O2 & IB@F3-F7 \\
\hline \multirow[t]{6}{*}{$R$} & 15 & IB@C4 & DT@C3 & IAC@F4-O2 & IA@O2 & DT@CZ \\
\hline & 16 & IB@C3 & DT@F3 & IS@CZ & IBC@F3-F7 & IAC@C4-F8 \\
\hline & 17 & IB@C3 & DT@F8 & IS@CZ & DT@F4 & IAC@C4-F8 \\
\hline & 18 & IB@C3 & DT@F3 & IS@CZ & DT@F4 & IAC@C4-F8 \\
\hline & 19 & IAC@P3-O1 & DT@F3 & IS@CZ & DT@F2 & IAC@F4-T4 \\
\hline & 20 & IAC@P3-O1 & IS@C3 & IS@CZ & DT@F2 & IAC@F4-T4 \\
\hline \multicolumn{7}{|c|}{$\begin{array}{l}\text { First letter: } I=\text { Increase, } D=\text { Decrease } \\
\text { Second and third letter: } D=\text { Delta }(0-4 \mathrm{~Hz}), T=\text { Theta }(4-8 \mathrm{~Hz}), A=\text { Alpha }(8-12 \mathrm{~Hz}), B=\text { Beta }(16-18 \mathrm{~Hz}) \text {, } \\
S=\text { SMR }(13-15 \mathrm{~Hz}), C=\text { Coherence }\end{array}$} \\
\hline
\end{tabular}

